\title{
Dynamic Analysis of Rotor Speed and Electrical Torque of Brushless Doubly Fed Induction Generator (BDFIG) Under Symmetrical and Unsymmetrical Faults
}

\author{
Javad Mahmoudi ${ }^{1, *}$, Seyed Zeinolabedin Moussavi ${ }^{2}$ and Esmail Mahmoodi ${ }^{3}$ \\ ${ }^{1}$ Electrical and Computer Engineering Department, Shahid Rejaee Teacher Training University, Tehran, Iran \\ ${ }^{2}$ Faculty of Electrical and Computer Engineering, Shahid Rejaee Teacher Training University, Tehran, Iran \\ ${ }^{3}$ Faculty of Agricultural Engineering, Shahrood University, Semnan, Iran
}

\begin{abstract}
The brushless doubly fed induction generator (BDFIG) has the potential to be employed as a variable speed wind turbine generator. Owing to brushless configuration of this generator, its reliability is higher than DFIG. Most of the grid faults are unsymmetrical. Hence, this paper analyzes dynamic behavior of BDFIG under symmetrical and unsymmetrical faults and presents dynamic models for both fault types. In order to validate the results of analysis, simulations have been carried out using MATLAB/Simulink software. Then, the control winding (CW) current is compared under symmetrical and unsymmetrical faults.
\end{abstract}

Keywords: Brushless doubly fed induction generator (BDFIG), Grid faults, Rotor speed, Dynamic modeling, Current winding.

\section{INTRODUCTION}

The evolution of technology related to wind systems industry leaded to the development of variable speed wind turbines that present advantages compared to the fixed speed wind turbines.

Thereupon, connection of wind farms to grid and analysis and improvement of their dynamic behavior regarding new grid codes have become important issues [1, 2].

The low-voltage ride-through capability of wind turbines with doubly-fed induction generators (DFIGs) has been widely studied in literature e.g. [3-5].

Also, many papers have been presented BDFIG modeling and control. An equivalent circuit is suggested and validated by means of experiments in [6]. A rotor flux oriented control schemes presented in $[7,8]$ and a unified reference frame $d-q$ model is verified experimentally in [9].

A brief description on structure of BDFIG, fundamentals of operation and its dynamic model for two sequences of machine is presented. In other part of this paper, the variations of fluxes and currents are analyzed using $d-q$ model and the simulation results for speed and currents are presented at the end. The

*Address correspondence to this author at the Electrical and Computer Engineering Department, Shahid Rejaee Teacher Training University, Tehran, Iran; Tel: +98-915-372-7855; Fax: +98-585-622-6450;

E-mail: jmahmoudi66@gmail.com analysis is based on a simplified vector model developed for the BDFIG with a nested-loop type of rotor in LVRT under three phase voltage dip $[10,11]$

\section{BDFIG STRUCTURE AND MODELING}

The BDFIG comprises two stator windings with different pole numbers to avoid direct coupling. The nested-loop type of rotor is the most well-known [11]. The power winding $(\mathrm{PW})$ is connected to mains and the control winding $(\mathrm{CW})$ is fed by a fractionally rated power electronic converter, as shown in Figure 1. The shaft angular speed, $\omega_{r}$ is determined as:

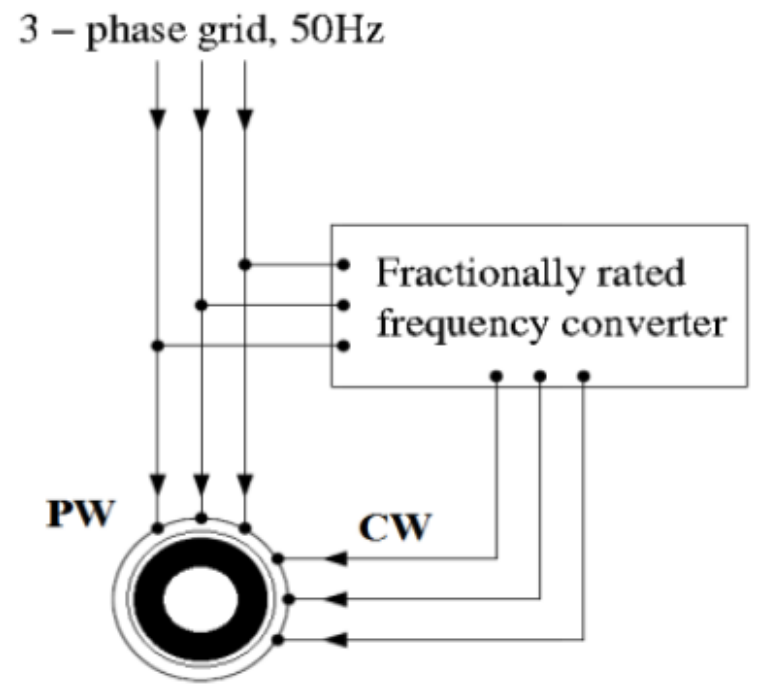

Figure 1: BDFIG structure.

$\omega_{\mathrm{r}}=\frac{\omega_{\mathrm{p}}+\omega_{\mathrm{c}}}{\mathrm{p}_{\mathrm{p}}+\mathrm{p}_{\mathrm{c}}}$ 
Where $p_{p}, p_{c}, \omega_{p}$ and $\omega_{c}$ are the PW and CW pole pair numbers and $P W$ and $C W$ angular frequencies, respectively. The BDFIG $d-q$ model in the $p_{p}$ pole pair synchronously rotating reference frame is stated as $[11,12]$ :

$$
\begin{aligned}
& \lambda_{\mathrm{p}}=\mathrm{L}_{\mathrm{p} p} \mathrm{i}_{\mathrm{p}}+\mathrm{L}_{\mathrm{Pr}_{\mathrm{r}}} \mathrm{i}_{\mathrm{r}} \\
& \lambda_{\mathrm{c}}=\mathrm{L}_{\mathrm{c}} \mathrm{i}_{\mathrm{c}}+\mathrm{L}_{\mathrm{cr}} \mathrm{i}_{\mathrm{r}} \\
& \lambda_{\mathrm{r}}=\mathrm{L}_{\mathrm{r}} \mathrm{i}_{\mathrm{r}}+\mathrm{L}_{\mathrm{pr}} \mathrm{i}_{\mathrm{p}}+\mathrm{L}_{\mathrm{cr}} \mathrm{i}_{\mathrm{c}} ; \\
& \mathrm{v}_{\mathrm{p}}=\mathrm{R}_{\mathrm{p}} \mathrm{i}_{\mathrm{p}}+\frac{\mathrm{d}\left(\lambda_{\mathrm{p}}\right)}{\mathrm{d}(\mathrm{t})}+\mathrm{j} \omega_{\mathrm{p}} \lambda_{\mathrm{p}} \\
& \mathrm{v}_{\mathrm{c}}=\mathrm{R}_{\mathrm{c}} \mathrm{i}_{\mathrm{c}}+\frac{\mathrm{d}\left(\lambda_{\mathrm{c}}\right)}{\mathrm{d}(\mathrm{t})}+\mathrm{j}\left(\omega_{\mathrm{p}}-\mathrm{Nr}_{\mathrm{r}}\right) \lambda_{\mathrm{c}} \\
& \mathrm{v}_{\mathrm{r}}=\mathrm{R}_{\mathrm{r}} \mathrm{i}_{\mathrm{r}}+\frac{\mathrm{d}\left(\lambda_{\mathrm{r}}\right)}{\mathrm{d}(\mathrm{t})}+\mathrm{j}\left(\omega_{\mathrm{p}}-\mathrm{p}_{\mathrm{p}} \omega_{\mathrm{r}}\right) \lambda_{\mathrm{r}}=0 ; \\
& \mathrm{T}_{\mathrm{e}}=-\frac{3}{2} * \mathrm{p}_{\mathrm{p}} \operatorname{Im}\left(\lambda_{\mathrm{p}}{ }^{*} \mathrm{i}_{\mathrm{p}}\right)-\frac{3}{2} * \mathrm{p}_{\mathrm{c}} \operatorname{Im}\left(\lambda_{\mathrm{c}} \mathrm{i}_{\mathrm{c}}{ }^{*}\right) \\
& \left(\mathrm{T}_{\mathrm{m}}-\mathrm{T}_{\mathrm{e}}\right)=\mathrm{J} \frac{\mathrm{d}\left(\omega_{\mathrm{r}}\right)}{\mathrm{d}(\mathrm{t})}+\mathrm{B} \omega_{\mathrm{r}}
\end{aligned}
$$

PI controllers have been used for speed and PW reactive power control by adjusting $\mathrm{V}_{\mathrm{qc}}$ and $\mathrm{V}_{\mathrm{dc}}$, respectively [13].

Neglecting $R_{p}$ in (5) leads to (10) and (11) for positive [13] and negative sequence fluxes of $\mathrm{PW}$ under fault conditions, respectively. These equations are in the PW reference frame.

$\lambda_{\mathrm{p}}+\approx \frac{\mathrm{V}_{\mathrm{p}-\mathrm{f}}}{\omega_{\mathrm{p}}} \mathrm{e}^{\mathrm{j} \omega \mathrm{pt}}+\frac{\mathrm{V}_{\mathrm{p}-0}-\mathrm{V}_{\mathrm{p}-\mathrm{f}}}{\omega_{\mathrm{p}}} \mathrm{e}^{-\sigma t}$

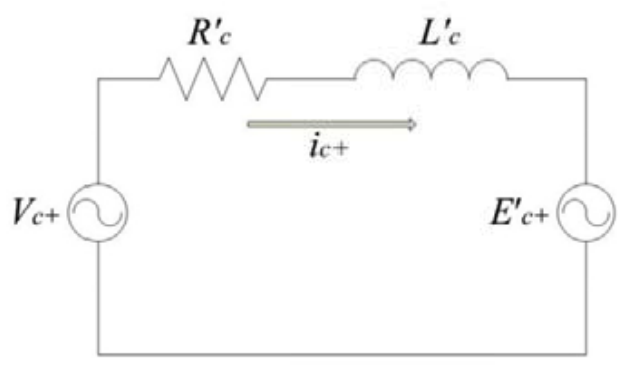

(a)

$$
\lambda_{\mathrm{p}}-\approx \frac{\mathrm{V}_{\mathrm{p}-\mathrm{f}}}{-\omega_{\mathrm{p}}} \mathrm{e}^{-\mathrm{j} \omega \mathrm{pt}}+\frac{\mathrm{V}_{\mathrm{p}-0}-\mathrm{V}_{\mathrm{p}-\mathrm{f}}}{-\omega_{\mathrm{p}}} \mathrm{e}^{-\sigma t}
$$

Combining (2)-(11) and neglecting rotor resistance, positive and negative sequence components of the $\mathrm{CW}$ voltage in the $\mathrm{CW}$ stationary reference frame are obtained as (12)-(14) with equivalent circuit model as Figure 2.

$$
\begin{aligned}
& \mathrm{R}_{\mathrm{c}}^{\prime}=\mathrm{R}_{\mathrm{c}}+\left(\frac{\mathrm{L}_{\mathrm{pr}} \mathrm{L}_{\mathrm{cr}}}{\mathrm{L}_{\mathrm{p}} \mathrm{L}_{\mathrm{r}}-\mathrm{L}_{\mathrm{pr}}^{2}}\right)^{2} \\
& \mathrm{~L}_{\mathrm{c}}^{\prime}=\mathrm{L}_{\mathrm{c}}-\frac{\mathrm{L}_{\mathrm{pr}} \mathrm{L}_{\mathrm{pr}}^{2}}{\mathrm{~L}_{\mathrm{p}} \mathrm{L}_{\mathrm{r}}-\mathrm{L}_{\mathrm{pr}}^{2}}
\end{aligned}
$$

$\mathrm{v}_{\mathrm{c}}^{-}=\mathrm{R}_{\mathrm{c}}^{\prime} \mathrm{i}_{\mathrm{c}}^{-}+\mathrm{L}_{\mathrm{c}}^{\prime} \frac{\mathrm{d}\left(\mathrm{i}_{\mathrm{c}}^{-}\right)}{\mathrm{d}(\mathrm{t})}+\mathrm{E}_{\mathrm{c}}^{\prime-}$

$\mathrm{E}_{\mathrm{c}}^{\prime+}=\mathrm{E}_{\mathrm{c} 1}^{\prime+}+\mathrm{E}_{\mathrm{c} 2}^{\prime+}$

$=\frac{1}{\omega_{p}} \frac{L_{p r} L_{c r}}{L_{p} L_{r}-L_{p r}^{2}}\left\{\left(\frac{L_{r} R_{p}}{L_{p} L_{r}-L_{p r}^{2}}+j\left(N_{r} \omega_{r}-\omega_{p}\right)\right) V_{p-f} e^{j\left(N_{r} \omega_{r}-\omega_{p}\right) t}\right.$

$\left.+\left(\frac{L_{r} R_{p}}{L_{p} L_{r}-L_{p r}^{2}}+j N_{r} \omega_{r}\right)\left(V_{p-0}-V_{p-f}\right) e^{j\left(N_{r} \omega_{r} t_{e}-\sigma t\right.}\right\}$

$\mathrm{E}_{\mathrm{c}}^{\prime-}=\mathrm{E}_{\mathrm{c} 1}^{--}+\mathrm{E}_{\mathrm{c} 2}^{-}$

$=\frac{1}{\omega_{p}} \frac{L_{p r} L_{c r}}{L_{p} L_{r}-L_{p r}^{2}}\left\{\left(\frac{L_{r} R_{p}}{L_{p} L_{r}-L_{p r}^{2}}-j\left(N_{r} \omega_{r}+\omega_{p}\right)\right) V_{p-f}^{-} e^{j\left(N_{r} \omega_{r}+\omega_{p}\right) t}\right.$

$\left.+\left(\frac{L_{r} R_{p}}{L_{p} L_{r}-L_{p r}^{2}}-j N_{r} \omega_{r}\right)\left(V_{p-0}^{-}-V_{p-f}^{-}\right) e^{j\left(N_{r} \omega_{r} t_{c}-\sigma t\right.}\right\}$

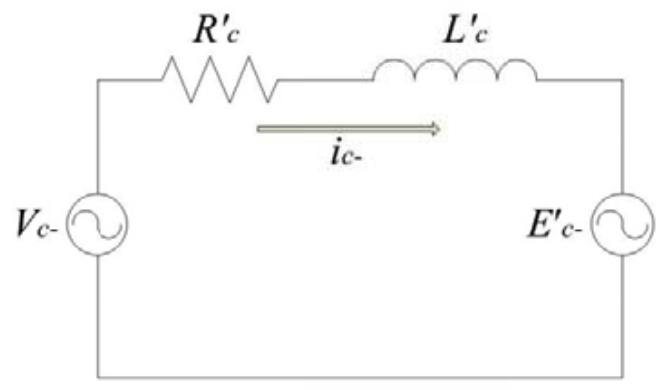

(b)

Figure 2: The transient CW model for (a) positive sequence and (b) negative sequence. 
In (12), $R_{c}^{\prime}$ and $L_{c}^{\prime}$ are transient resistance and inductance of $\mathrm{CW}$ under - symmetrical or unsymmetrical voltage dip conditions, respectively.

As mentioned in [13], $\mathrm{E}_{\mathrm{c}}^{\prime+}$ is a positive sequence that rotates in the same direction as the injected voltage and $\mathrm{E}_{\mathrm{c}}^{\prime-}$ is a negative sequence EMF that rotates in the opposite direction as the injected voltage, i.e. the EMF frequency of $\mathrm{CW}$ is $-\omega_{\mathrm{p}}$ with respect to rotor.

The equations (14) and (15) are EMF of CW during voltage dip. As can be seen from (14) and (15), the EMF has two parts. The first part, $\mathrm{E}_{\mathrm{cl}}^{\prime \pm}$, depends upon pre-fault terminal voltage $\left(\mathrm{V}_{0-\mathrm{p}}\right)$ of BDFIG and the second one, $\mathrm{E}_{\mathrm{c} 2}^{\prime \pm}$, depends on severity of voltage dip $\left(V_{p-f}-V_{p-0}\right)$. On the other hand, the fault type affects on the induced EMF by changing the frequency, It means that in negative sequence, the value of $\left(\mathrm{N}_{\mathrm{r}} \omega_{\mathrm{r}}+\omega_{\mathrm{p}}\right)$ is larger than in positive sequence $\left(\mathrm{N}_{\mathrm{r}} \omega_{\mathrm{r}}-\omega_{\mathrm{p}}\right)$.

Consequently, the EMF of CW depends on the prefault terminal voltage and rotor speed.

Hence, the CW current can be calculated by (16) and (17).

$i_{c}^{+}=I_{c 1}^{+} e^{-\frac{R_{c}^{\prime}}{L_{c}^{\prime}} t}+I_{c 2}^{+} e^{j\left(N_{r} \omega_{r}-\omega_{p}\right) t}+I_{c 3}^{+} e^{j N_{r} \omega_{r} t_{e}-\sigma t}$

$i_{c}^{-}=I_{c 1}^{-} e^{-\frac{R_{c}^{\prime}}{L_{c}^{\prime}} t}+I_{c 2}^{-} e^{j\left(N_{r} \omega_{r}+\omega_{p}\right) t}+I_{c 3}^{-} e^{j N_{r} \omega_{r} t_{e}-\sigma t}$

This currents have two oscillating parts and one DC part (first part). The first part damps rapidly by $\frac{\mathrm{R}_{\mathrm{c}}^{\prime}}{\mathrm{L}_{\mathrm{c}}^{\prime}}$, time constant. This part can be neglected for analysis of fault comparison because of it is same for each faults and negative/positive sequence.

The maximum magnitudes of second and third parts $\left(\mathrm{I}_{\mathrm{c} 2}^{ \pm}, \mathrm{I}_{\mathrm{c} 3}^{ \pm}\right)$are calculated by maximum EMF (for each part separately) and their impedances as (18) and (19).

$$
\begin{aligned}
\max \left(\mathrm{i}_{\mathrm{c}}^{+}\right)= & \max \left(\mathrm{I}_{\mathrm{c} 2}^{+} \mathrm{e}^{\mathrm{j}\left(\mathrm{N}_{\mathrm{r}} \omega_{\mathrm{r}}-\omega_{\mathrm{p}}\right) \mathrm{t}}+\mathrm{I}_{\mathrm{c} 3}^{+} \mathrm{e}^{\mathrm{j}\left(\mathrm{N}_{\mathrm{r}} \omega_{\mathrm{r}} \mathrm{t}_{\mathrm{e}}-\sigma \mathrm{t}\right)}\right. \\
= & \frac{\max \left(\mathrm{E}_{\mathrm{c} 1}^{\prime+}\right)}{\mathrm{Z}_{\mathrm{c}}^{\prime+}}+\frac{\max \left(\mathrm{E}_{\mathrm{c} 2}^{\prime+}\right)}{\sqrt{\left(\mathrm{R}_{\mathrm{c}}^{\prime}\right)^{2}+\mathrm{L}_{\mathrm{c}}^{\prime 2}\left(\mathrm{~N}_{\mathrm{r}} \omega_{\mathrm{r}}\right)^{2}}} \\
\max \left(\mathrm{i}_{\mathrm{c}}^{-}\right)= & \max \left(\mathrm{I}_{\mathrm{c} 2}^{-} \mathrm{e}^{\mathrm{j}\left(\mathrm{N}_{\mathrm{r}} \omega_{\mathrm{r}}+\omega_{\mathrm{p}}\right) \mathrm{t}}+\mathrm{I}_{\mathrm{c} 3}^{-} \mathrm{e}^{\mathrm{j} \mathrm{N}_{\mathrm{r}} \mathrm{\omega}_{\mathrm{r}} \mathrm{t}_{\mathrm{e}}-\sigma \mathrm{t}}\right. \\
= & \frac{\max \left(\mathrm{E}_{\mathrm{c} 1}^{\prime-}\right)}{\mathrm{Z}_{\mathrm{c}}^{\prime-}}+\frac{\max \left(\mathrm{E}_{\mathrm{c} 2}^{\prime-}\right)}{\sqrt{\left(\mathrm{R}_{\mathrm{c}}^{\prime}\right)^{2}+\mathrm{L}_{\mathrm{c}}^{\prime 2}\left(\mathrm{~N}_{\mathrm{r}} \omega_{\mathrm{r}}\right)^{2}}}
\end{aligned}
$$

Regarding (14) and (15), the maximum magnitude of EMF $\left(\mathrm{E}_{\mathrm{c} 1}^{\prime \pm}, \mathrm{E}_{\mathrm{c} 2}^{\prime \pm}\right)$ is obtained as:

$$
\begin{aligned}
& \max \left(\mathrm{E}_{\mathrm{c} 1}^{\prime \pm}\right)=\frac{1}{\omega_{\mathrm{p}}} \frac{\mathrm{L}_{\mathrm{pr}} \mathrm{L}_{\mathrm{cr}}}{\mathrm{L}_{\mathrm{p}} \mathrm{L}_{\mathrm{r}}-\mathrm{L}_{\mathrm{pr}}^{2}} \\
& \left(\sqrt{\left(\frac{\mathrm{R}_{\mathrm{p}} \mathrm{L}_{\mathrm{r}}}{\mathrm{L}_{\mathrm{p}} \mathrm{L}_{\mathrm{r}}-\mathrm{L}_{\mathrm{pr}}^{2}}\right)^{2}+\left(\mathrm{N}_{\mathrm{r}} \omega_{\mathrm{r}} \pm \omega_{\mathrm{p}}\right)^{2}}\right) \mathrm{V}_{\mathrm{p}-0}^{ \pm} \\
& \max \left(\mathrm{E}_{\mathrm{c} 2}^{\prime \pm}\right)=\frac{1}{\omega_{\mathrm{p}}} \frac{\mathrm{L}_{\mathrm{pr}} \mathrm{L}_{\mathrm{cr}}}{\mathrm{L}_{\mathrm{p}} \mathrm{L}_{\mathrm{r}}-\mathrm{L}_{\mathrm{pr}}^{2}} \\
& \left(\sqrt{\left(\frac{\mathrm{R}_{\mathrm{p}} \mathrm{L}_{\mathrm{r}}}{\mathrm{L}_{\mathrm{p}} \mathrm{L}_{\mathrm{r}}-\mathrm{L}_{\mathrm{pr}}^{2}}\right)^{2}+\left(\mathrm{N}_{\mathrm{r}} \omega_{\mathrm{r}}\right)^{2}}\right)\left(\mathrm{V}_{\mathrm{p}-0}^{ \pm}-\mathrm{V}_{\mathrm{p}-\mathrm{f}}^{ \pm}\right)
\end{aligned}
$$

Similarly, the maximum EMF is calculated for postfault conditions as follows:

$$
\begin{aligned}
& \max \left(\mathrm{E}_{\mathrm{cl}}^{\prime \pm}\right)=\frac{1}{\omega_{\mathrm{p}}} \frac{\mathrm{L}_{\mathrm{pr}} \mathrm{L}_{\mathrm{cr}}}{\mathrm{L}_{\mathrm{p}} \mathrm{L}_{\mathrm{r}}-\mathrm{L}_{\mathrm{pr}}^{2}} \\
& \left(\sqrt{\left(\frac{\mathrm{R}_{\mathrm{p}} \mathrm{L}_{\mathrm{r}}}{\mathrm{L}_{\mathrm{p}} \mathrm{L}_{\mathrm{r}}-\mathrm{L}_{\mathrm{pr}}^{2}}\right)^{2}+\left(\mathrm{N}_{\mathrm{r}} \omega_{\mathrm{r}} \pm \omega_{\mathrm{p}}\right)^{2}}\right) \mathrm{V}_{\mathrm{p}-\mathrm{f}}^{ \pm} \\
& \max \left(\mathrm{E}_{\mathrm{c} 2}^{\prime \pm}\right)=\frac{1}{\omega_{\mathrm{p}}} \frac{\mathrm{L}_{\mathrm{pr}} \mathrm{L}_{\mathrm{cr}}}{\mathrm{L}_{\mathrm{p}} \mathrm{L}_{\mathrm{r}}-\mathrm{L}_{\mathrm{pr}}^{2}} \\
& \left(\sqrt{\left(\frac{\mathrm{R}_{\mathrm{p}} \mathrm{L}_{\mathrm{r}}}{\mathrm{L}_{\mathrm{p}} \mathrm{L}_{\mathrm{r}}-\mathrm{L}_{\mathrm{pr}}^{2}}\right)^{2}+\left(\mathrm{N}_{\mathrm{r}} \omega_{\mathrm{r}}\right)^{2}}\right)\left(\mathrm{V}_{\mathrm{p}-\mathrm{f}}^{ \pm}-\mathrm{V}_{\mathrm{p}-0}^{ \pm}\right)
\end{aligned}
$$

The term $\left(\frac{1}{\omega_{p}} \frac{L_{p r} L_{c r}}{L_{p} L_{r}-L_{p r}^{2}}\right)$ is the same for pre- and post-fault conditions as well as symmetrical and unsymmetrical faults. This term is shown by $L$ in the following.

$$
\text { In (22) and (23), the term }\left(\frac{\mathrm{R}_{\mathrm{p}} \mathrm{L}_{\mathrm{r}}}{\mathrm{L}_{\mathrm{p}} \mathrm{L}_{\mathrm{r}}-\mathrm{L}_{\mathrm{pr}}^{2}}\right) \text { is negligible }
$$
in comparison to $\left(\mathrm{N}_{\mathrm{r}} \omega_{\mathrm{r}} \pm \omega_{\mathrm{p}}\right)^{2}$ and $\left(\mathrm{N}_{\mathrm{r}} \omega_{\mathrm{r}}\right)^{2}$ under faults. The positive and negative sequences of EMF can be presented as Tables 1 and $\mathbf{2}$ for fault-on and post-fault conditions, respectively.

Table 3 shows the transient impedance in both of sequences. As can be seen, the transient impedance is higher in the case of negative sequence. 
Table 1: Maximum EMF of CW for both Sequences During Voltage Dip Recovery

\begin{tabular}{|c|c|c|}
\hline \multirow{2}{*}{ Sequence } & \multicolumn{2}{|c|}{$\mathrm{EMF}_{\max }$} \\
\cline { 2 - 3 } & $\mathrm{E}_{\mathrm{cl-max}}^{\prime}$ & $\mathrm{E}_{\mathrm{c} 2-\max }$ \\
\hline \hline Positive sequence & $\mathrm{L}\left(\mathrm{N}_{\mathrm{r}} \omega_{\mathrm{r}}-\omega_{\mathrm{p}}\right) \mathrm{V}_{\mathrm{p}-\mathrm{f}}^{+}$ & $\mathrm{L}\left(\mathrm{N}_{\mathrm{r}} \omega_{\mathrm{r}}\right)\left(\mathrm{V}_{\mathrm{p}-0}-\mathrm{V}_{\mathrm{p}-\mathrm{f}}^{+}\right)$ \\
\hline Negative sequence & $\mathrm{L}\left(\mathrm{N}_{\mathrm{r}} \omega_{\mathrm{r}}+\omega_{\mathrm{p}}\right) \mathrm{V}_{\mathrm{p}-\mathrm{f}}^{-}$ & $\mathrm{L}\left(\mathrm{N}_{\mathrm{r}} \omega_{\mathrm{r}}\right)\left(\mathrm{V}_{\mathrm{p}-0}-\mathrm{V}_{\mathrm{p}-\mathrm{f}}^{-}\right)$ \\
\hline
\end{tabular}

Table 2: Maximum EMF Induced in the CW after Voltage Recovery

\begin{tabular}{|c|c|c|}
\hline \multirow{2}{*}{ Sequence } & & \multicolumn{2}{|c|}{$\mathrm{EMF}_{\max }$} \\
\cline { 2 - 3 } & $\mathrm{E}_{\mathrm{c} 1-\mathrm{max}}^{\prime}$ & $\mathrm{E}_{\mathrm{c} 2-\mathrm{max}}^{\prime}$ \\
\hline \hline Positive sequence & $\mathrm{L}\left(\mathrm{N}_{\mathrm{r}} \omega_{\mathrm{r}}-\omega_{\mathrm{p}}\right) \mathrm{V}_{\mathrm{p}-0}$ & $\mathrm{~L}\left(\mathrm{~N}_{\mathrm{r}} \omega_{\mathrm{r}}\right)\left(\mathrm{V}_{\mathrm{p}-\mathrm{f}}^{+}-\mathrm{V}_{\mathrm{p}-0}\right)$ \\
\hline Negative sequence & $\mathrm{L}\left(\mathrm{N}_{\mathrm{r}} \omega_{\mathrm{r}}+\omega_{\mathrm{p}}\right) \mathrm{V}_{\mathrm{p}-0}$ & $\mathrm{~L}\left(\mathrm{~N}_{\mathrm{r}} \omega_{\mathrm{r}}\right)\left(\mathrm{V}_{\mathrm{p}-\mathrm{f}}^{-}-\mathrm{V}_{\mathrm{p}-0}\right)$ \\
\hline
\end{tabular}

Table 3: Maximum EMF of CW for both Sequences During Voltage Dip Recovery

\begin{tabular}{|c|c|c|}
\hline \multirow{2}{*}{ Sequence } & \multicolumn{2}{|c|}{$\begin{array}{c}\text { Transient impedance of CW } \\
\mathbf{Z}_{\mathrm{c}}^{\prime}=\mathbf{R}_{\mathrm{c}}^{\prime}+\mathbf{j}_{\mathrm{c}}^{\prime}\end{array}$} \\
\cline { 2 - 3 } & $\mathbf{R}^{\prime}$ & $\mathbf{X}_{\mathrm{c}}^{\prime}$ \\
\hline \hline Positive sequence & $\mathrm{R}_{\mathrm{c}}+\left(\frac{\mathrm{L}_{\mathrm{pr}} \mathrm{L}_{\mathrm{cr}}}{\mathrm{L}_{\mathrm{p}} \mathrm{L}_{\mathrm{r}}-\mathrm{L}_{\mathrm{pr}}^{2}}\right)^{2}$ & $\left(\mathrm{~L}_{\mathrm{c}}-\frac{\mathrm{L}_{\mathrm{pr}} \mathrm{L}_{\mathrm{cr}}^{2}}{\mathrm{~L}_{\mathrm{p}} \mathrm{L}_{\mathrm{r}}-\mathrm{L}_{\mathrm{pr}}^{2}}\right)\left(\mathrm{N}_{\mathrm{r}} \omega_{\mathrm{r}}-\omega_{\mathrm{p}}\right)$ \\
\hline Negative sequence & $\mathrm{R}_{\mathrm{c}}+\left(\frac{\mathrm{L}_{\mathrm{pr}} \mathrm{L}_{\mathrm{cr}}}{\mathrm{L}_{\mathrm{p}} \mathrm{L}_{\mathrm{r}}-\mathrm{L}_{\mathrm{pr}}^{2}}\right)^{2}$ & $\left(\mathrm{~L}_{\mathrm{c}}-\frac{\mathrm{L}_{\mathrm{pr}} \mathrm{L}_{\mathrm{cr}}^{2}}{\mathrm{~L}_{\mathrm{p}} \mathrm{L}_{\mathrm{r}}-\mathrm{L}_{\mathrm{pr}}^{2}}\right)\left(\mathrm{N}_{\mathrm{r}} \omega_{\mathrm{r}}+\omega_{\mathrm{p}}\right)$ \\
\hline
\end{tabular}

As it can be seen from Table 1, the first part of EMF $\left(E_{\mathrm{cl}-\max }^{\prime}\right)$ depends on $\mathrm{N}_{\mathrm{r}} \omega_{\mathrm{r}} \pm \omega_{\mathrm{p}}$ whereas the second part is the same for both sequences. This means that the first part of EMF will be greater for unsymmetrical faults with equal voltage dip severity due to their negative sequence. On the other hand, the second part is independent from sequences and terminal voltage $\left(\mathrm{V}_{\mathrm{p}-\mathrm{f}}^{ \pm}\right)$determines its maximum magnitude. Table 4 shows this EMF for 3-phase, 2-phase and 1-phase to ground faults in the PW terminals. The terminal voltages are stated as:

$\mathrm{V}_{\mathrm{a}}=\mathrm{V}_{\mathrm{m}} \cos \left(\omega_{\mathrm{p}} \mathrm{t}\right) ; \mathrm{V}_{\mathrm{b}}=\mathrm{V}_{\mathrm{m}} \cos \left(\omega_{\mathrm{p}} \mathrm{t}-120\right) ;$

$\mathrm{V}_{\mathrm{c}}=\mathrm{V}_{\mathrm{m}} \cos \left(\omega_{\mathrm{p}} \mathrm{t}+120\right)$

As shown in Figure 3, voltage dips of $0.75 \%$ for 100 $\mathrm{ms}$ at $240 \mathrm{~V}$ are considered in accordance to $\mathrm{E}$. ON Netz grid code for symmetrical and unsymmetrical faults.
The zero sequence voltage is smaller than the others, so it can be negligible for calculation of EMF maximum magnitude. On the other hand, cross coupling don't make between $\mathrm{PW}$ and $\mathrm{CW}$ because of its zero frequency $\left(\omega_{p}=0\right)$ then DC fluxes which produced by zero sequence can't induce CW voltage and current. Therefore:

$\mathrm{V}_{\mathrm{p}-\mathrm{f}}^{ \pm}=\sqrt{\mathrm{V}_{\mathrm{d}-\mathrm{f}}^{2}+\mathrm{V}_{\mathrm{q}-\mathrm{f}}^{2}+\mathrm{V}_{0-\mathrm{f}}^{2}} \approx \sqrt{\mathrm{V}_{\mathrm{d}-\mathrm{f}}^{2}+\mathrm{V}_{\mathrm{q}-\mathrm{f}}^{2}}$

$V_{p-f}$ has close values for 3-phase and 2-phase fault $\left(V_{p-f} \simeq 0.3 V_{m}\right)$. Hence $E_{c l-\max }^{\prime}$ of negative sequence is higher than that of positive sequence. Also, $\mathrm{E}_{\mathrm{c} 2-\max }^{\prime}$ is the same for both of sequences? Hence, the EMF of 2phase faults is higher than that of 3-phase faults. Under 1-phase fault conditions, $V_{p-f}$ is higher than other fault types and hence, the second part of EMF will be very low. 


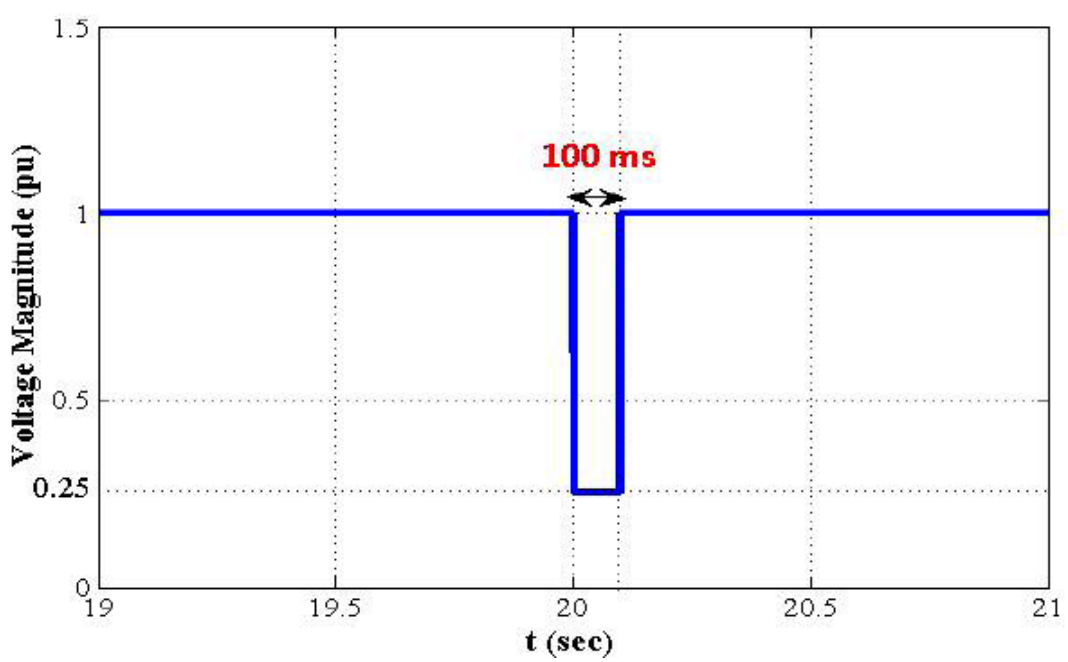

Figure 3: E. ON Netz grid code for all the fault types.

Table 4: PW Terminal Voltage $\left(\mathrm{V}_{\mathrm{p}-\mathrm{f}}\right)$ During Different Voltage Dip Types

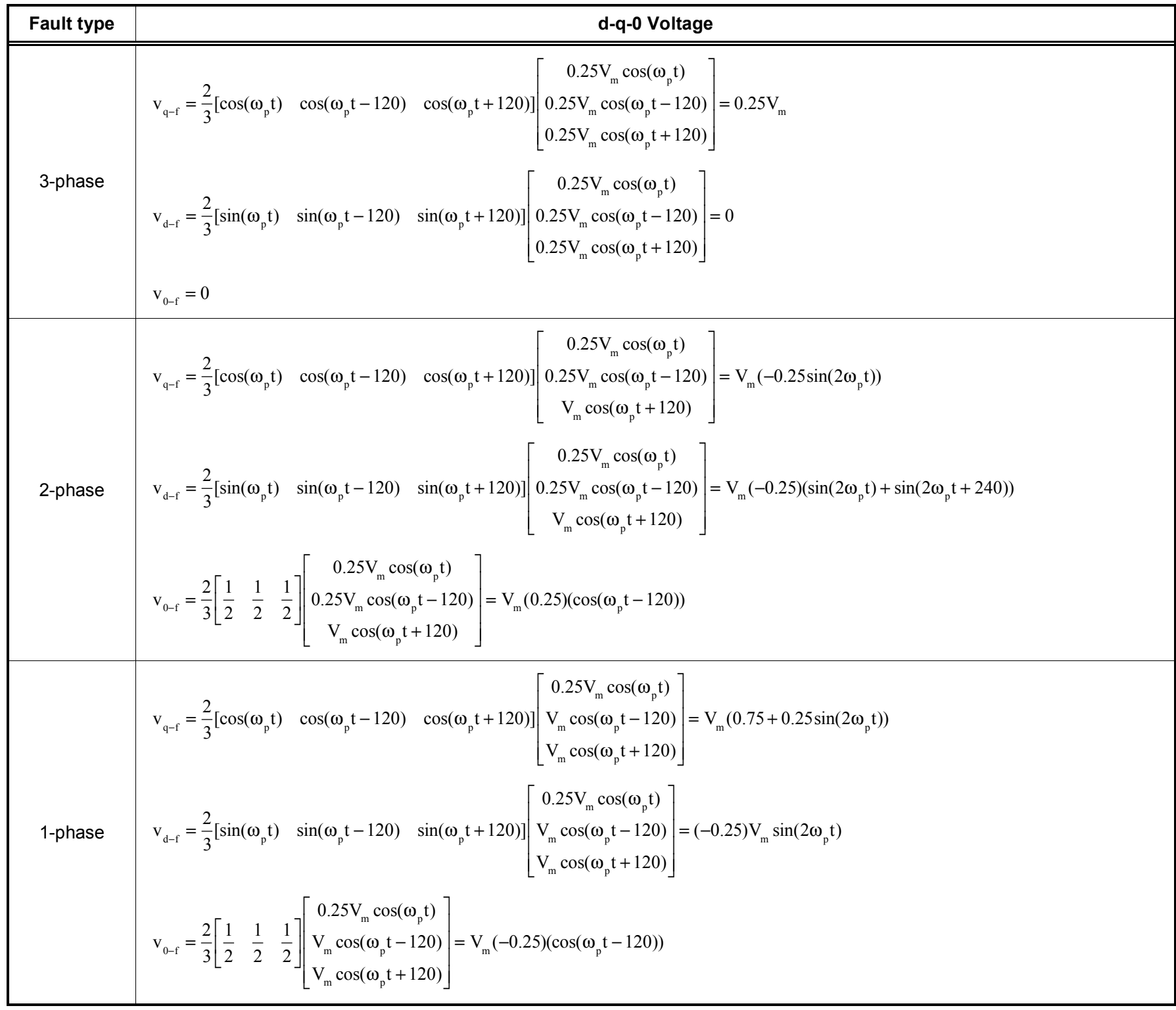




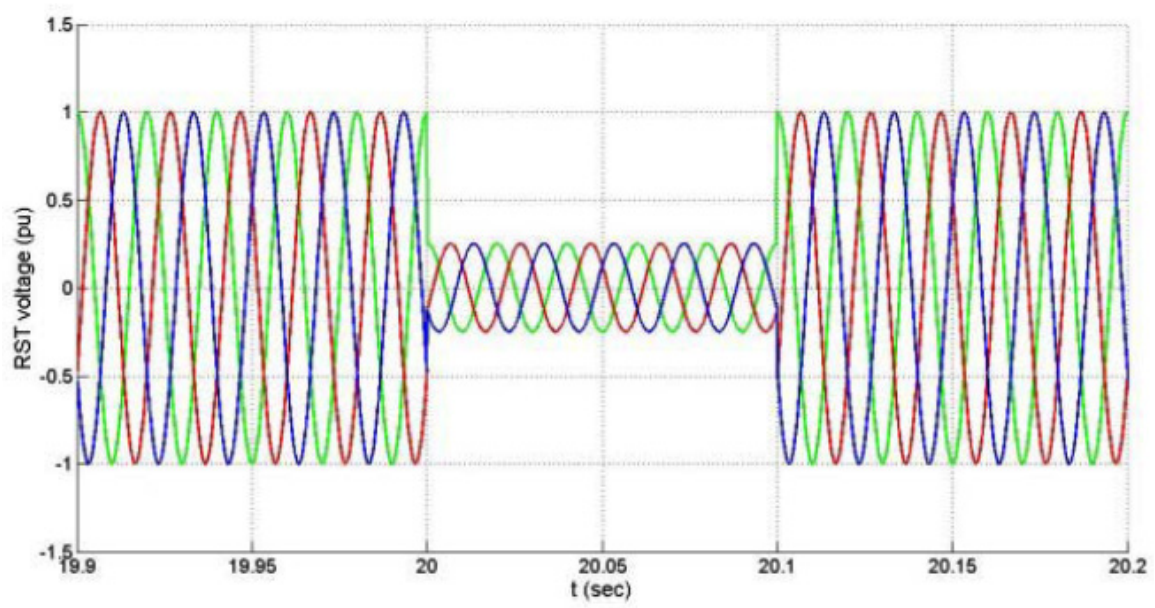

Figure 4: The abc PW voltage.

As mentioned earlier, the EMF of 2-phase fault has the greatest value among the faults. Although this results in increased induced current in the $\mathrm{CW}$, but the transient impedance will also be higher during this type of fault (see Table 3). Obviously, higher transient impedance leads to more highly damped oscillations of electromagnetic torque.

\section{SIMULATION AND VALIDATION}

The machine model is implemented in MATLAB/Simulink with the parameters given in the Appendix. The nominal torque of $100 \mathrm{Nm}$ and the rated grid voltage of $240 \mathrm{~V}$ are applied before voltage dip.

When the E. ON Netz is applied to PW terminals for symmetrical and unsymmetrical faults, following results obtained.

\subsection{The 3-Phase Fault}

Appling the fault code on PW caused to terminal voltage drop then the fluxes decrease in air gap. The rotor speed increases by this flux growth reduction, therefor the electromagnetic torque try to control it then $\mathrm{T}_{\mathrm{e}}$ decreases.

A three phase voltage dip is applied at $\mathrm{t}=20 \mathrm{~s}$ on the generator terminals, as shown in Figure 4 . The variation of rotor speed and electromagnetic torque is illustrated in Figures $\mathbf{5}$ and $\mathbf{6}$, respectively.

As can be seen from Figure 6, $T_{e}$. increases when the fault occurs. This is because of instant reduction of flux in CW. The fluctuations after voltage recovery are more than when fault occurs. This is caused by low speed and torque before recovery which results high overshoot when voltage returns to nominal value.

\subsection{The 2-Phase Fault}

In this part, 2-phase to ground fault analyzes. By grounding of $b$ and $c$ phases of $\mathrm{PW}$, following results obtained. As mentioned before, the fluctuation of $T_{e}$ is more than symmetrical fault because of the negative sequence of EMF.

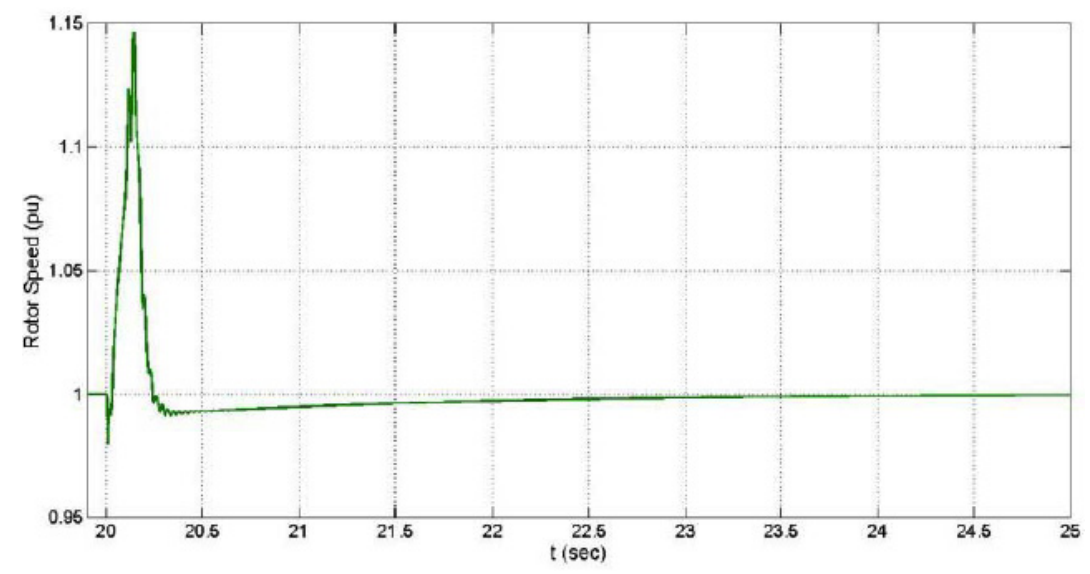

Figure 5: The rotor speed under 3-phase fault. 


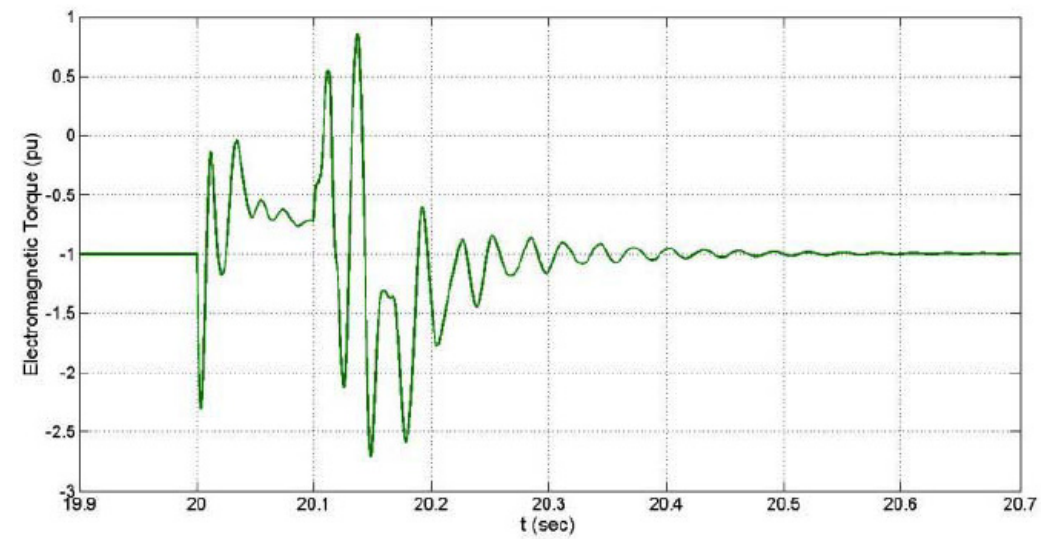

Figure 6: The electromagnetic torque under 3-phase fault.

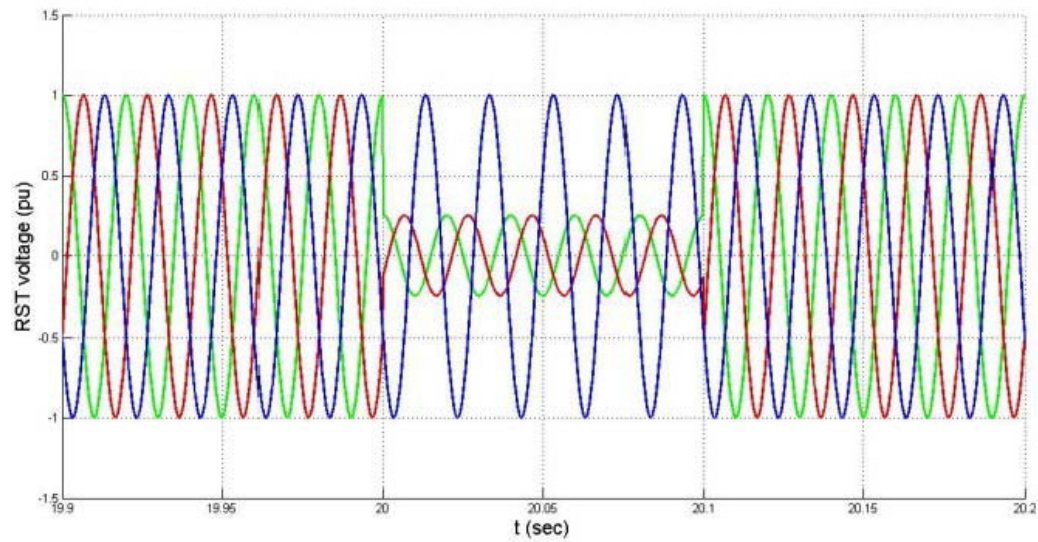

Figure 7: The abc PW voltage.

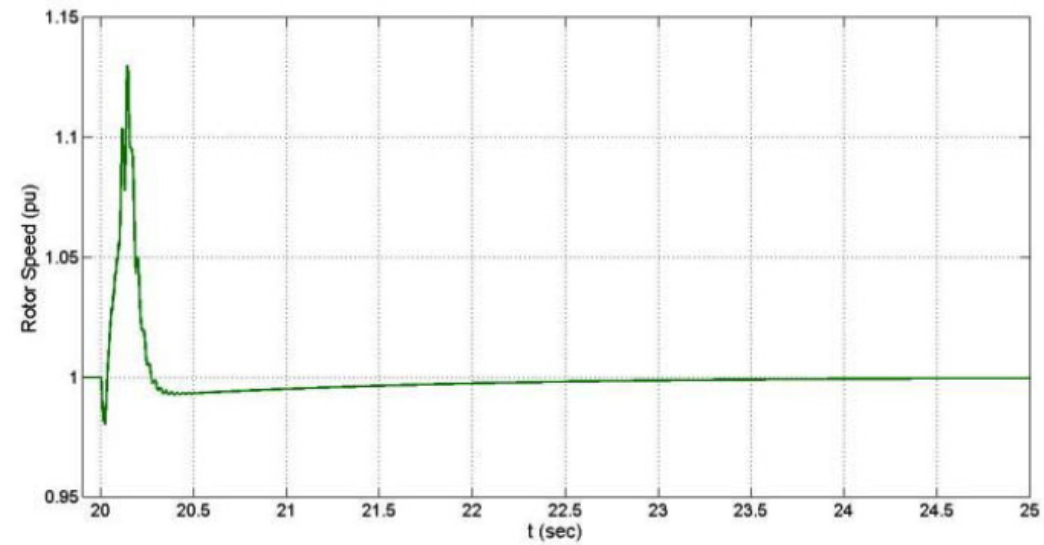

Figure 8: The rotor speed under 2-phase fault.

When a two-phase to ground fault occurs, the value of $T_{e}$ is lower than 3-phase fault. As it represented, the fluxes in 2-phase fault have lower reduction than 3phase. Therefore, the speed and $T_{e}$ were greater.

On the other hand, due to rotated field at reverse direction, the torque will have more fluctuations than the case of three phase faults.

\subsection{The 1-Phase Fault}

When this fault occurs, the fault-on voltage $\left(V_{p-f}\right)$ is higher than other fault types. This results in less reduction of the PW flux linkage and hence, less fluctuation on the electromagnetic torque. Figures 10 to 12 show the terminal voltage, rotor speed and electromagnetic torque for this fault type, respectively. 


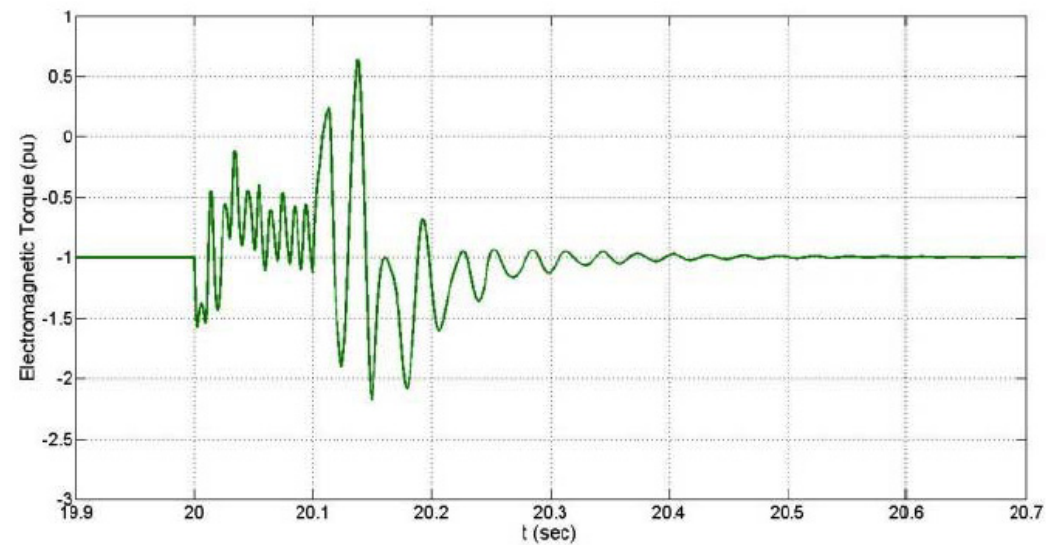

Figure 9: The electromagnetic torque under 2-phase fault.

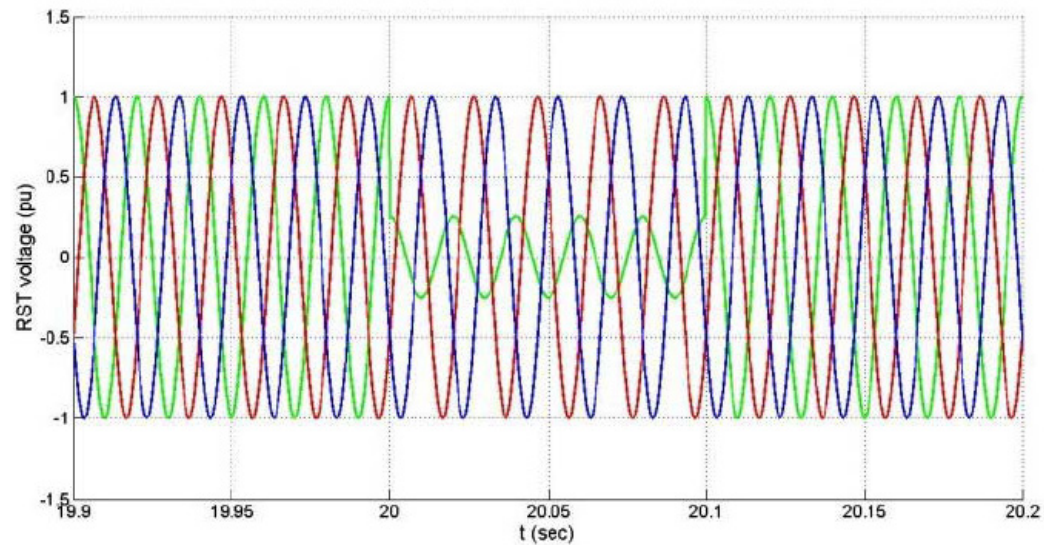

Figure 10: The abc PW voltage.

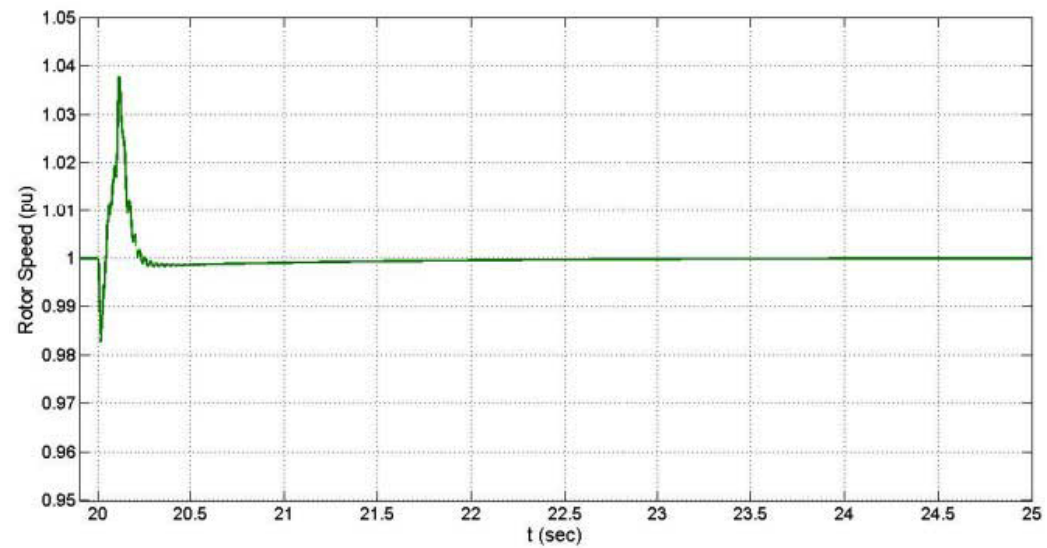

Figure 11: The rotor speed under 1-phase fault.

The rotor speed and electromagnetic torque have lower fluctuations than 3-phase and 2-phase faults as it analyzed before.

However, as observed in the simulation results, damping of fluctuations is higher than other fault types because of two reasons; One, lower dip voltage and second, larger transient impedance.

\subsection{CW Current}

In order to compare the influence of different types of faults on BDFIG, the CW current peak should be compared.

$$
I_{c w}=\sqrt{I_{d-c}^{2}+I_{q-c}^{2}}
$$




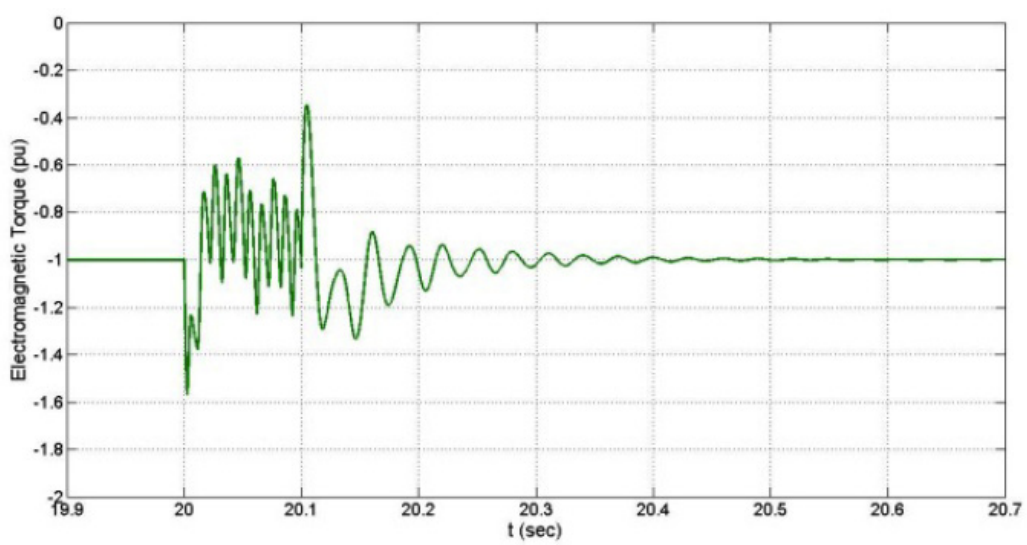

Figure 12: The electromagnetic torque under 1-phase fault.

Another criterion is the settling time of CW current (the time required for reaching $\mathrm{CW}$ current to $95 \%$ of steady state current) and number of peaks up on 1.5 pu. These factors are shown in Table $\mathbf{5}$. Figures 13 to 15 show the CW current under different fault conditions.
As shown in Figures 13 to 15, the CW current has higher peak value under 2-phase fault conditions. Fluctuation of post-fault CW current of 2-phase fault is lower than that of 3-phase fault due to higher transient impedance. The EMF amplitude is the smallest in the case of 1-phase to ground fault. Thereupon, the peak

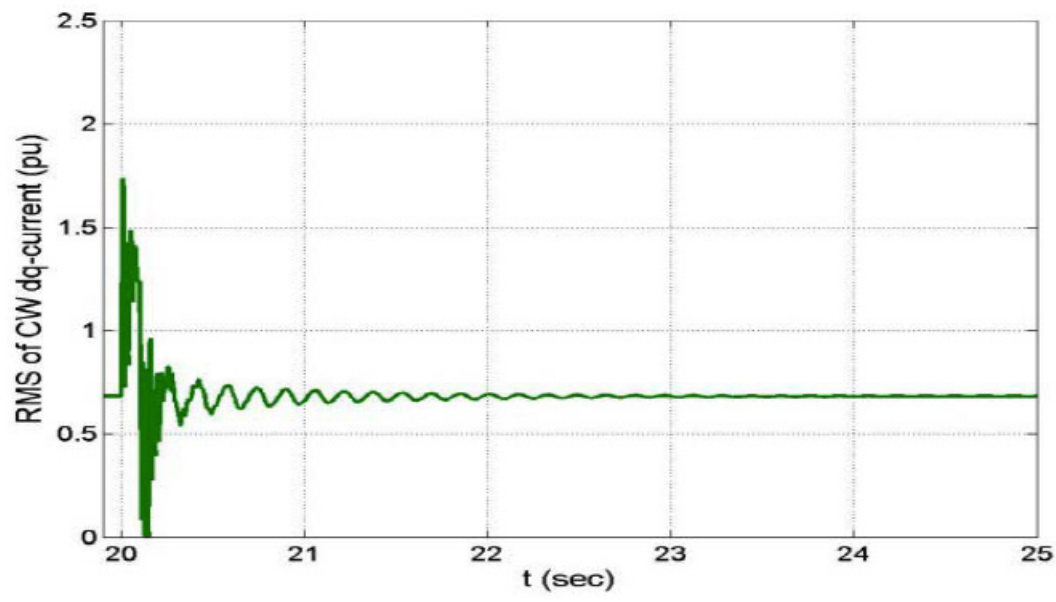

Figure 13: CW current during the 3-phase fault.

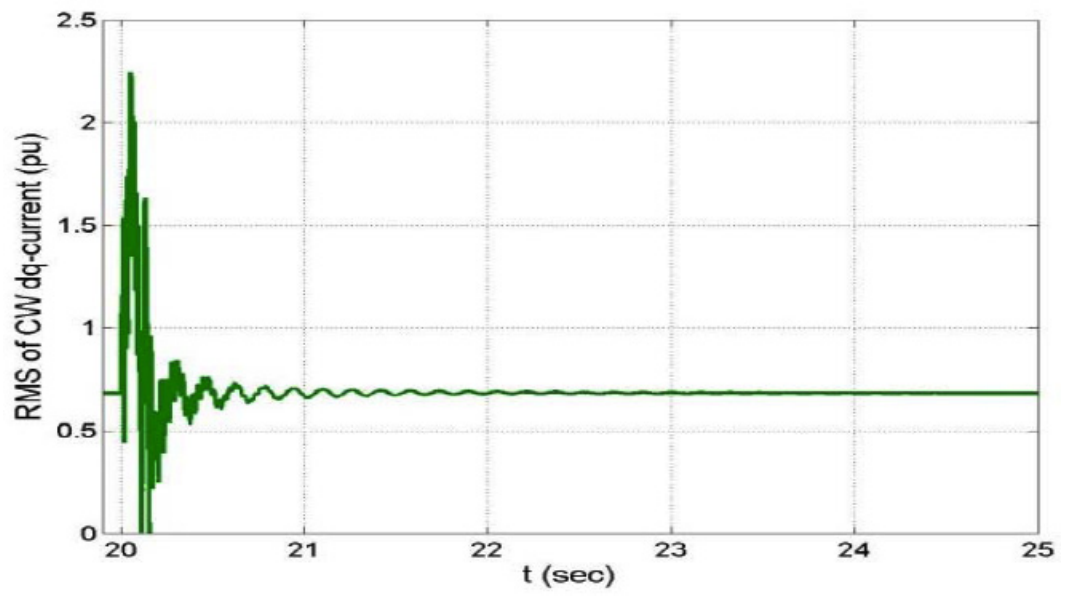

Figure 14: CW current under the 2-phase fault. 


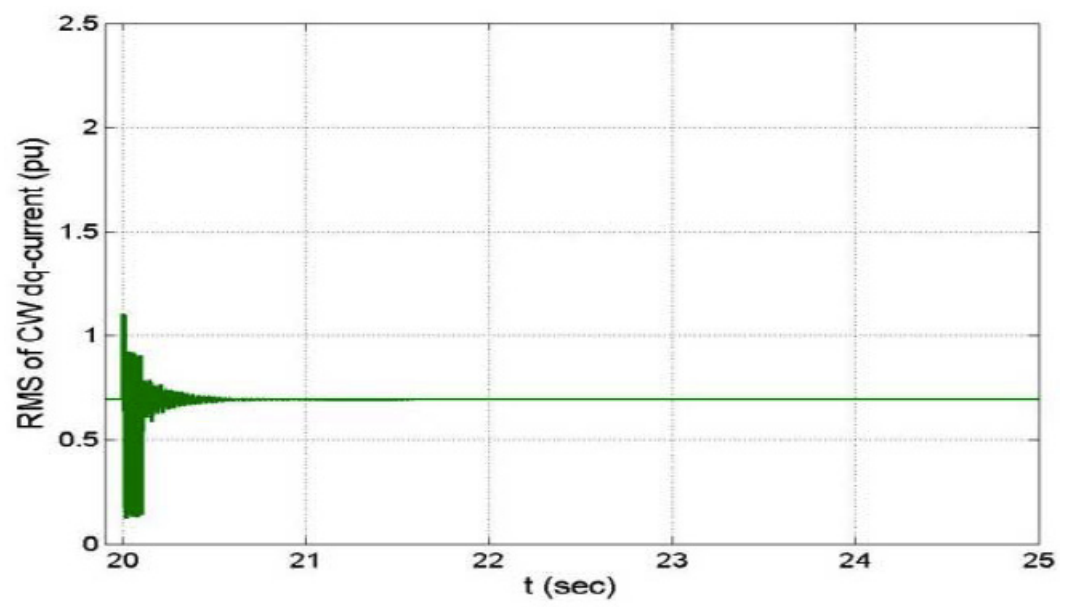

Figure 15: CW current under 1-phase to ground fault.

Table 5: The Criteria for Comparison of $\mathrm{I}_{\mathrm{cw}}$ for each Fault Type

\begin{tabular}{|c|c|c|c|}
\hline Fault type & Peak value of $\mathrm{I}_{\mathbf{c w}}(\mathbf{p u})$ & Settling time (sec) & Number of peaks upon 1.5 pu \\
\hline \hline 3-phase to ground & 1.75 & 2.88 & 2 \\
\hline 2-phase to ground & 2.25 & 2.07 & 7 \\
\hline 1-phase to ground & 1.15 & 0.43 & 0 \\
\hline
\end{tabular}

value of CW current under this fault is the lowest, too. On the other hand, negative transient impedance leads to highly damped CW current.

The fluctuation of $\mathrm{CW}$ current during 2-phase fault is 7 times upon 1.5 pu (see Table 5). This can damage the convertor switches.

As expected, the simulation results validate dynamic model analysis. It is obtained from theoretical analysis and simulations that 2-phase fault leads to higher peak value of $\mathrm{CW}$ current among various types of faults. However, the CW current damping is the highest in the case of 2-phase fault because of higher transient impedance.

\section{CONCLUSION}

Dynamic performance of BDFIG is presented in different types of faults and the simulation results are used to validate the analysis. The mathematical $\mathrm{dq}$ model is used to obtain the induced EMF in the CW.

\section{APPENDIX}

Table A1: Prototype BDFIG Specifications

\begin{tabular}{|c|c|c|c|}
\hline Parameter & Value & Parameter & Value \\
\hline$f_{p}$ & $50 \mathrm{~Hz}$ & Frame size & D180 \\
\hline $\mathrm{L}_{\mathrm{p}}$ & $0.3498 \mathrm{H}$ & $\mathrm{p}_{\mathrm{p}}$ & 2 \\
\hline $\mathrm{L}_{\mathrm{c}}$ & $0.3637 \mathrm{H}$ & $\mathrm{p}_{\mathrm{c}}$ & 4 \\
\hline$L_{r}$ & $0.0044521 \mathrm{mH}$ & $\mathrm{N}_{\mathrm{r}}$ & 6 \\
\hline $\mathrm{L}_{\mathrm{pr}}$ & $0.0031 \mathrm{H}$ & Stator slots & 48 \\
\hline $\mathrm{L}_{\mathrm{cr}}$ & $0.0022 \mathrm{H}$ & Rotor slots & 36 \\
\hline $\mathbf{R}_{\mathbf{p}}$ & $2.3 \Omega$ & PW rated voltage & $240 \mathrm{~V}$ in $50 \mathrm{~Hz}$ \\
\hline $\mathbf{R}_{\mathrm{c}}$ & $4 \Omega$ & $\mathrm{CW}$ rated voltage & $240 \mathrm{~V}$ in $50 \mathrm{~Hz}$ \\
\hline $\mathbf{R}_{\mathrm{r}}$ & $0.00012967 \Omega$ & $\mathrm{PW}$ rated current & $8 \mathrm{~A}$ \\
\hline $\mathrm{J}$ & $0.53 \mathrm{Kg} \cdot \mathrm{m}^{2}$ & $\mathrm{CW}$ rated current & $8 \mathrm{~A}$ \\
\hline B &.$s$ & Rated Torque & $50 \mathrm{Nm}$ \\
\hline
\end{tabular}


Unsymmetrical faults have applied to investigate the performance of BDFIG torque and effect of produced EMF of $C W$ in transient state. Then, the dynamic model of BDFIG is implemented in MATLAB/Simulink to verify the results for three-phase, two-phase and singlephase to ground faults. The results show that twophase to ground leads to maximum EMF with highest oscillation and peak of CW current and hence, it is the most severe fault type from LVRT point of view. Furthermore, when an unsymmetrical fault occurs, the negative sequence fluxes result in oscillations of electromagnetic torque and rotor speed.

\section{REFERENCES}

[1] Grid Connection Code - extra high voltage Transpowerstromubertrangungsgmbh, April 2007-2009. [Online]. Available from: http://www.tennettso.de

[2] Lima FKA, Luna A, Rodrigues $P$, Watanabe EH, Blaabjerg F. Rotor voltage dynamics in the doubly fed induction generator during grid faults. IEEE Trans Power Electron 2010; 25(1): 118-130. http://dx.doi.org/10.1109/TPEL.2009.2025651

[3] McMahon RA, Roberts PC, Wang X, Tavner PJ. Performance of BDFM as generator and motor. Electr Power Applicat IEE Proc 2006; 153(2): 289-299. http://dx.doi.org/10.1049/ip-epa:20050289

[4] Lopez J, Sanchis P, Roboam X, Marroyo L. Dynamic behavior of the doubly fed induction generator during threephase voltage dips. IEEE Trans Energy Convers 2007; 22(3): 707-717. http://dx.doi.org/10.1109/TEC.2006.878241

[5] Lopez J, Gubia E, Sanchis P, Roboam X, Marroyo L. Wind turbines based on doubly fed induction generator under asymmetrical voltage dips. IEEE Trans Energy Convers 2008; 23(1): 321-330.

http://dx.doi.org/10.1109/TEC.2007.914317
[6] Roberts PC, McMahon RA, Tavner PJ, Maciejowski JM, Flack TJ. Equivalent circuit for the brushless doubly fed machine (BDFM) including parameter estimation and experimental verification. IEE Proc - Electric Power Applicat 2005; 152: 933-942. http://dx.doi.org/10.1049/ip-epa:20045106

[7] Zhau D, Spee R, Alexander GC. Experimental evaluation of a rotor flux oriented control algorithm for brushless doublyfed machines. IEEE Trans Power Electron. 1997; 12(1): 7278

http://dx.doi.org/10.1109/63.554171

[8] Poza J, Oyarbide E, Roya D, Rodriguez M. Vector contro design and experimental evaluation for the brushless doubly fed machine. IEE Proc - Electric Power Applicat 2009; 3(4): 247-256.

http://dx.doi.org/10.1049/iet-epa.2008.0090

[9] Tohidi S, Zolghadri M, Oraee H, Oraee A. Dynamic modeling of a wind turbine with brushless doubly fed induction generator. Power Electron Drive Systems Technology Conf PEDSTC 2012: 490-494.

http://dx.doi.org/10.1109/PEDSTC.2012.6183379

[10] Poza J, Oyarbide E, Sarasola I, Rodriguez M. Unified reference frame dq model of the brushless doubly fed machine. IET Electric Power Applicat 2009; 153(5): 42204228.

[11] McMahon RA, Wang X, Abdi E, Roberts PJ, Jagiela M. The BDFM as a generator in wind turbines, Power Electron Motion Control Conf 12th Int 2006: 1859-1865. http://dx.doi.org/10.1109/EPEPEMC.2006.4778676

[12] Roberts PC. A study of brushless doubly-fed (induction) machines. Ph.D dissertation, University of Cambridge 2005.

[13] Tohidi S, Oraee H, Zolghadri M, Shao S, Tavner P. Analysis and Enhancement of Low Voltage Ride-through Capability of Brushless Doubly Fed Induction Generator. IEEE Trans Ind Electron 2013; 60(3): 1146-1155. http://dx.doi.org/10.1109/TIE.2012.2190955

(C) 2014 Mahmoudi et al.; Licensee Lifescience Global.

This is an open access article licensed under the terms of the Creative Commons Attribution Non-Commercial License (http://creativecommons.org/licenses/by-nc/3.0/) which permits unrestricted, non-commercial use, distribution and reproduction in any medium, provided the work is properly cited. 